\title{
Islet Cell Surface Antibodies in Type 1 (Insulin-Dependent) Diabetes Mellitus: Use of Human Fetal Pancreas Cultures as Substrate
}

\author{
R. Pujol-Borrell, E. L. Khoury and G. F. Bottazzo \\ Department of Immunology, Middlesex Hospital Medical School, London, UK
}

\begin{abstract}
Summary. Sixteen pancreases from 11-24 week old human fetuses were cultured for up to 11 days to investigate islet cell surface antibodies. Hormonal content and presence of cytoplasmic autoantigen were assessed by immunofluorescence with specific antihormone sera and high titre cytoplasmic islet cell antibody positive sera. Viable islet cells cultured on coverslips were tested with 21 islet cell antibody positive sera from Type 1 (insulin-dependent) diabetics, one islet cell antibody positive serum from a non-diabetic and four normal control sera. Surface binding immunoglobulins were detected by indirect immunofluorescence in nine out of 11 newly diagnosed Type 1 diabetics and in two out of ten longstanding diabetics with another coexistent autoimmune endocrinopathy. The four-layer double immunofluorescence technique showed that the surface antibody stained insulin secreting cells, but owing to rarity of $A$ and $D$ cells in the fetal cultures it has not yet been possible to exclude the reactivity of islet cell surface antibodies with glucagon or somatostatin cells.
\end{abstract}

Key words: Cytoplasmic islet cell antibodies, islet cell surface reacting antibodies, Type 1 (insulin-dependent) diabetes.

The detection of immunological 'markers' at the time of diagnosis in most cases of Type 1 (insulin-dependent) diabetes, has led to a better understanding of the pathogenetic mechanisms which may be involved in causing the disease [1]. The well described islet cell antibodies (ICA) are directed against a cytoplasmic antigen common to the four types of endocrine cells recognised in the islets of Langerhans [2]. It is unlikely that these antibodies play a significant role in the initial destruction of the B cells since in viable cells, in- tracytoplasmic antigens are inaccessible to circulating immunocytes or immunoglobulins. If an antibody is involved in the initial damage it should react with a cell surface antigen confined to the B cell. Membrane reactive antibodies have been detected in a variety of classical organ specific autoimmune disorders: e.g. autoimmune thyroid disease [3,4], atrophic gastritis [5] and Addison's disease [6]. Such antibodies may damage cells either by complement-dependent lysis or by killer ( $\mathrm{K}$ cell) mediated mechanisms.

Maclaren et al. [7] reported the presence of islet cell surface antibodies (ICSA) in $87 \%$ of sera from recent onset Type 1 diabetic children, using immunofluorescence on an insulinoma cell line established in 1959. Unfortunately this line is now extinct and the results could not be reproduced with other insulinomas. In 1978 Lernmark et al. [8] used a similar technique on dispersed rat islet cells in suspension and found positive results in $32 \%$ of cases of Type 1 diabetes and $4 \%$ of sera from healthy children. Although not all the cells in their preparations showed surface fluorescence with positive sera, no attempts were made to prove that the staining was confined to $B$ cells.

Some degree of uncertainly remains regarding the organ and species specificity of ICSA as detected by the above methods. It is known that fetal and newborn pancreases contain a high proportion of endocrine cells and that human fetal pancreas can be cultured successfully [9]. So far these cultures have been used mainly for metabolic studies and for organ transplantation [10]. These studies have shown that fetal B cells release insulin following glucose stimulation, albeit less than adult cells. Both insulin release and the insulin response to different stimuli can be improved after 7-12 days in culture [11]. The establishment of a culture system with normal human fetal pancreatic islet cells could clarify the characteristics of ICSA. The aim of the present preliminary studies was to deter- 
mine whether ICSA could be detected using human fetal islet cells in monolayer cultures and to try and characterise the exact nature of the cells with which these antibodies react.

\section{Patients and Methods}

\section{Patients'Sera}

We tested serum samples from 11 newly diagnosed Type 1 diabetics (taken $<8$ weeks after the onset of symptoms). All these sera were $\mathrm{ICA}-\mathrm{IgG}$ positive and all but one also showed complement fixing ability (CF-ICA) [12]. None possessed any other organ specific autoantibodies, i. e. thyroglobulin or thyroid microsomal (measured by passive haemagglutination, Thymune- $T$ \& $\mathrm{M}$, Wellcome Reagents, Beckenham, UK); or gastric parietal cell or adrenal cortex (tested by indirect immunofluorescence). Ten sera from longstanding Type 1 diabetics with another coexistent autoimmune endocrinopathy (three primary myxoedema, four Graves' disease, one pernicious anaemia, and two with coexistent Addison's disease and pernicious anaemia) were also examined [13]. All ten sera were ICA-IgG positive but only five had CF-ICA, and each serum also showed circulating antibodies corresponding to the affected organ. One ICA positive non-diabetic autoimmune polyendocrine case and four normal healthy controls without a family history of diabetes mellitus were also tested. All the sera were heat inactivated at $56{ }^{\circ} \mathrm{C}$ for $30 \mathrm{~min}$ to prevent cytotoxic effects and stored at $-20{ }^{\circ} \mathrm{C}$.

\section{Substrate}

Fetal pancreas: sixteen pancreases from 11-24 week old fetuses were obtained from approved terminations and spontaneous abortions performed in various hospitals in the London area. The tissue was collected and processed under sterile conditions within $2 \mathrm{~h}$ of delivery. After careful trimming of the pancreas from remnants of gut and spleen, the tissue was minced into fine pieces (approximately $1 \mathrm{~mm}^{3}$ ) and washed with culture medium 199 (Flow Laboratories, Irvine, UK) containing added $\mathrm{NaHCO}_{3}(350 \mathrm{mg} / \mathrm{ml})$, penicillin $(300 \mathrm{U} / \mathrm{ml})$, streptomycin $(300 \mu \mathrm{g} / \mathrm{ml})$, glucose $(1 \mathrm{mg} / \mathrm{ml})$ and bovine serum albumin $(2 \mathrm{~g} / 1)$. The pieces were hand shaken at $37^{\circ} \mathrm{C}$ with $5 \mathrm{ml}$ culture medium supplemented with $15 \mathrm{mg}$ collagenase (Type IV, Worthington Biochemical Corporation, Freehold, New Jersey, USA). On three occasions a mixture of $0.25 \%$ trypsin (Difco Laboratories, West Molesey, Surrey, UK) and collagenase was used instead. After $12-15 \mathrm{~min}$ the reaction was stopped by diluting the digest with $20 \mathrm{ml}$ culture medium followed by two consecutive washings and spinnings at $100 \times g$ for $5 \mathrm{~min}$.

The pellet so obtained was resuspended in $1 \mathrm{ml}$ culture medium supplemented with 30\% heat inactivated fetal calf serum (Gibco Biocult, Glasgow, UK). Cell viability was assessed by differential staining with acridine orange/ethidium bromide using fluorescence microscopy. Preparations of approximately $70 \%$ viable cells were used for further staining experiments. An accurate cell count at this stage was not feasible as most pancreatic cells were in clusters and only gross estimation was attempted. The number of cells obtained from each pancreas ranged between $5 \times 10^{4}$ and $5 \times 10^{5}$. Aliquots of $10^{4}$ cells from the final suspensions were used to prepare cytocentrifuge smears which were subsequently fixed in acetone and stored at $-70^{\circ} \mathrm{C}$ for immunofluorescence staining. A similar amount of cells was plated on glass coverslips $(13 \mathrm{~mm}$ diameter) placed in multiwell plates (Linbro, Flow Laboratories, Irvine, UK) and culture medium plus $30 \%$ fetal calf serum was added to a final volume of $0.5 \mathrm{ml} /$ well. The cultures were kept at $37^{\circ} \mathrm{C}$ in a $5 \% \mathrm{CO}_{2}$ humidified incubator for a period of 4-11 days. Medium was changed every 3 days. The cultures were inspected daily with a phase contrast inverted microscope and when a minimum of $50 \%$ of cells were attached and spread on the coverslips, the preparation was considered suitable for staining experiments. To enhance the cell attachment to the glass, the culture medium was supplemented with the supernatant of actively growing fetal fibroblasts. Of the 16 pancreases processed, 10 fulfilled the necessary conditions for surface staining: i.e. cell viability and ability of the cells to adhere to the coverslips during culture. The number of cultures obtained from each pancreas ranged from $6-30$. Two pancreases were from blood group 0 fetuses, four were blood group $\mathrm{A}$ and one of blood group B. The remaining organs could not be typed for blood group as the terminations were performed by aspiration.

\section{Immunofluorescence Staining Procedures}

Cytoplasmic:for the staining with anti-hormone sera, the substrates were prepared in three different ways: (1) cryostat sections (2) acetone-fixed cytocentrifuge smears and (3) as acetone-fixed monolayers of cultured cells. The following antisera were employed: guinea-pig anti-insulin serum (GP-15 Miles, Elkhart, Indiana, USA) at a dilution of $1: 20$, rabbit anti-glucagon serum at a dilution of $1: 10$ and rabbit antisomatostatin serum at a dilution of $1: 50$ (kindly donated by Drs. J. Biener, Düsseldorf, FRG and M.Dubois, Nouzilly, France, respectively). Normal guinea-pig serum or a pool of normal rabbit sera were always incubated in parallel at the same dilution as controls. After 2-h incubations at room temperature with individual antisera, the preparations were exposed to antirabbit or anti-guinea-pig globulin labelled with fluorescein or rhodamine (Nordic Pharmaceuticals and Diagnostics, BerchemAntwerpen, Holland). These and the subsequent preparations were examined under a Zeiss fluorescence microscope equipped with epi-illumination and phase contrast. In addition, a strongly positive ICA serum was applied to the above substrates, which were then stained by classical indirect immunofluorescence techniques to assess the cytoplasmic autoantigen content of the endocrine cells.

Cell surface: four to 11 day old viable monolayers of human pancreatic fetal cells were used. After washing in culture medium the coverslips were incubated with $100 \mu$ of the prediluted diabetic or control serum $(1: 2)$ for $30 \mathrm{~min}$ at room temperature, followed by a similar incubation with $100 \mu$ of either sheep anti-human Fab or sheep anti-human IgG fluorescent conjugates (Wellcome Reagents, Beckenham, UK) at dilutions of $1: 40$ and $1: 20$ respectively. Between and after incubations the monolayers were washed by dipping the coverslips repeatedly into beakers containing culture medium. The cells were then fixed in $5 \%$ acetic acid in ethanol at $-20^{\circ} \mathrm{C}$ for $10 \mathrm{~min}$ and mounted in glycerol on a microscope slide. Each serum was tested a minimum of six times, and on at least two different pancreases.

Double labelled immunofluorescence: the viable pancreatic monolayers were first incubated with the patients' sera as described, followed by a rhodamine labelled anti-human IgG conjugate to reveal the membrane staining. The cultures were then fixed in acetone for $5 \mathrm{~min}$ to expose the cytoplasmic antigens and incubated firstly with the guinea-pig anti-insulin serum and subsequently with fluorescein labelled anti-guinea-pig conjugate.

Absorptions: six surface positive sera were retested by immunofluorescence on viable pancreatic monolayers after absorption with blood group $\mathrm{AB}$ human erythrocytes (three volumes of packed cells/volume serum, for $2 \mathrm{~h}$ at $4{ }^{\circ} \mathrm{C}$ ).

Immunoreactive insulin reactivity measurement: was performed by means of a double-antibody radioimmunoassay. The lower limit of sensitivity of this assay is $2-4 \mathrm{mU} / 1$. 


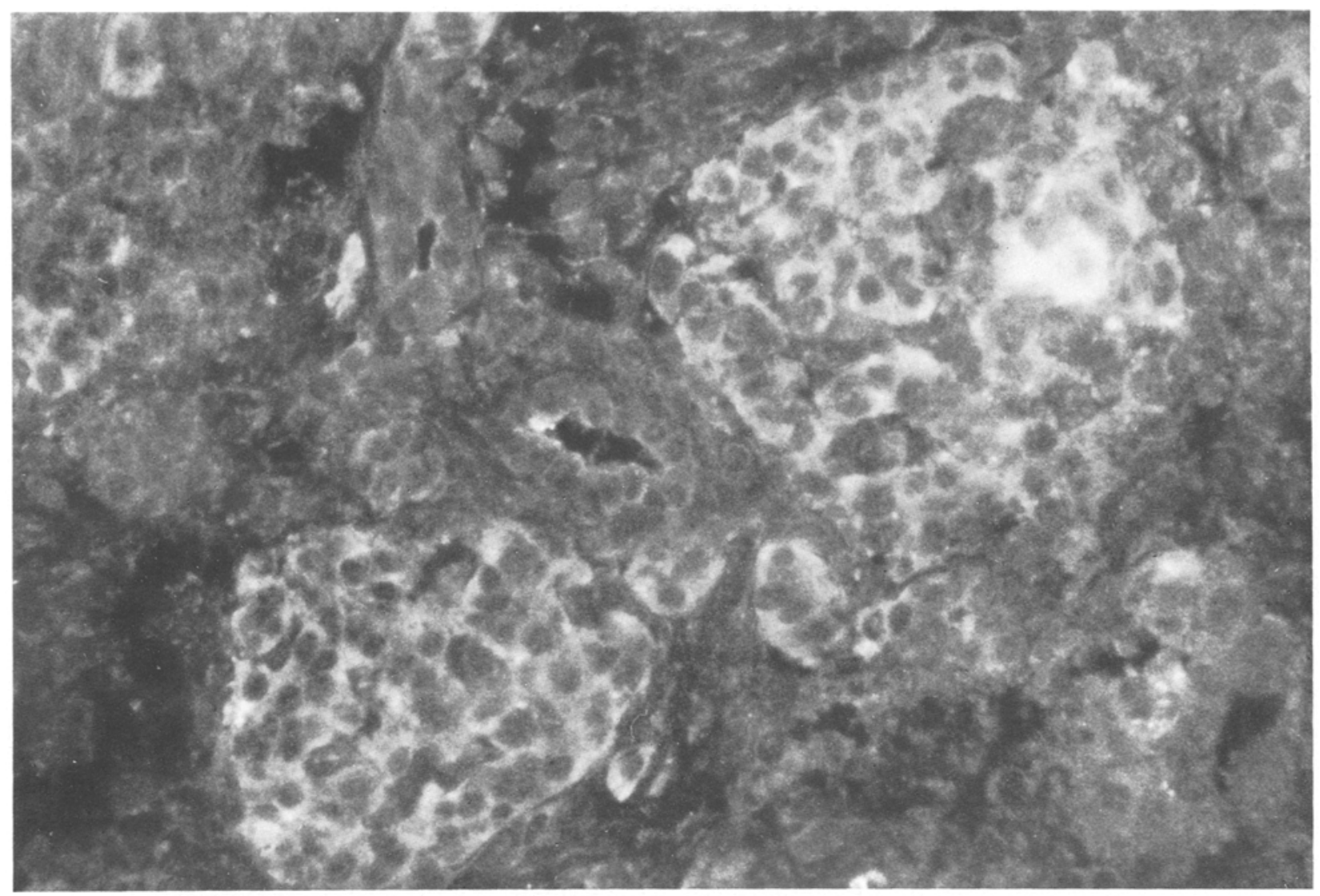

Fig. 1. Cryostat section of 20 week old human fetal pancreas stained by indirect immunofluorescence for islet cell antibodies

\section{Results}

\section{Identification of the Endocrine Cells}

Cryostat sections: immunofluorescent staining with anti-insulin serum showed the presence of insulin containing cells in three pancreases of 12,16 and 18 weeks gestational age. The ICA positive serum produced a diffuse positive cytoplasmic staining on the whole islet (Fig. 1), similar to that observed on adult pancreases, which clearly demonstrates that the cytoplasmic autoantigen involved in ICA is present as early as week 12 of fetal development. To eliminate possible interference of blood group antigens in the islet staining when using human sera, blood group 0 sera containing high titre iso-haemagglutinins were applied to the sections. Only capillary vessel staining was obtained, and this was completely removed by absorbing the serum with blood group $\mathrm{AB}$ erythrocytes.

Cytocentrifuge smears: in 30 smears examined from four pancreases the appearance of the different cell types was similar by phase contrast and a distinction on a purely morphological basis was difficult. When the specific hormone antisera were applied 6\%-10\% of the cells were B cells, $4 \%-6 \%$ were A cells and only a few $D$ cells were observed. The ICA positive sera produced a positive immunofluorescence on $20 \%$ of the cells in smears, although the staining was less intense than that obtained with the anti-insulin serum.

Cultures: the follow-up of the cultures showed that pancreatic islet cells need a considerable period (7-22 days) to attach to and spread on glass coverslips. The use of supernatant from actively growing fetal fibroblasts and a high concentration $(30 \%)$ of fetal calf serum reduced this period, allowing use of the monolayers after 4-6 days' culture. The release of immunoreactive insulin into the culture media persisted for up to 19 days at a steadily declining rate. The concentration of immunoreactive insulin in the supernatants was initially in the range of $200 \mathrm{mU} / 1$, while at day 10 it was approximately $50 \mathrm{mU} / 1$. The immunofluorescent staining of fixed monolayers with anti-insulin made it possible to recognise B cells. They appeared smaller than exocrine cells, with a more regular round nucleus and darker cytoplasm. The propor- 

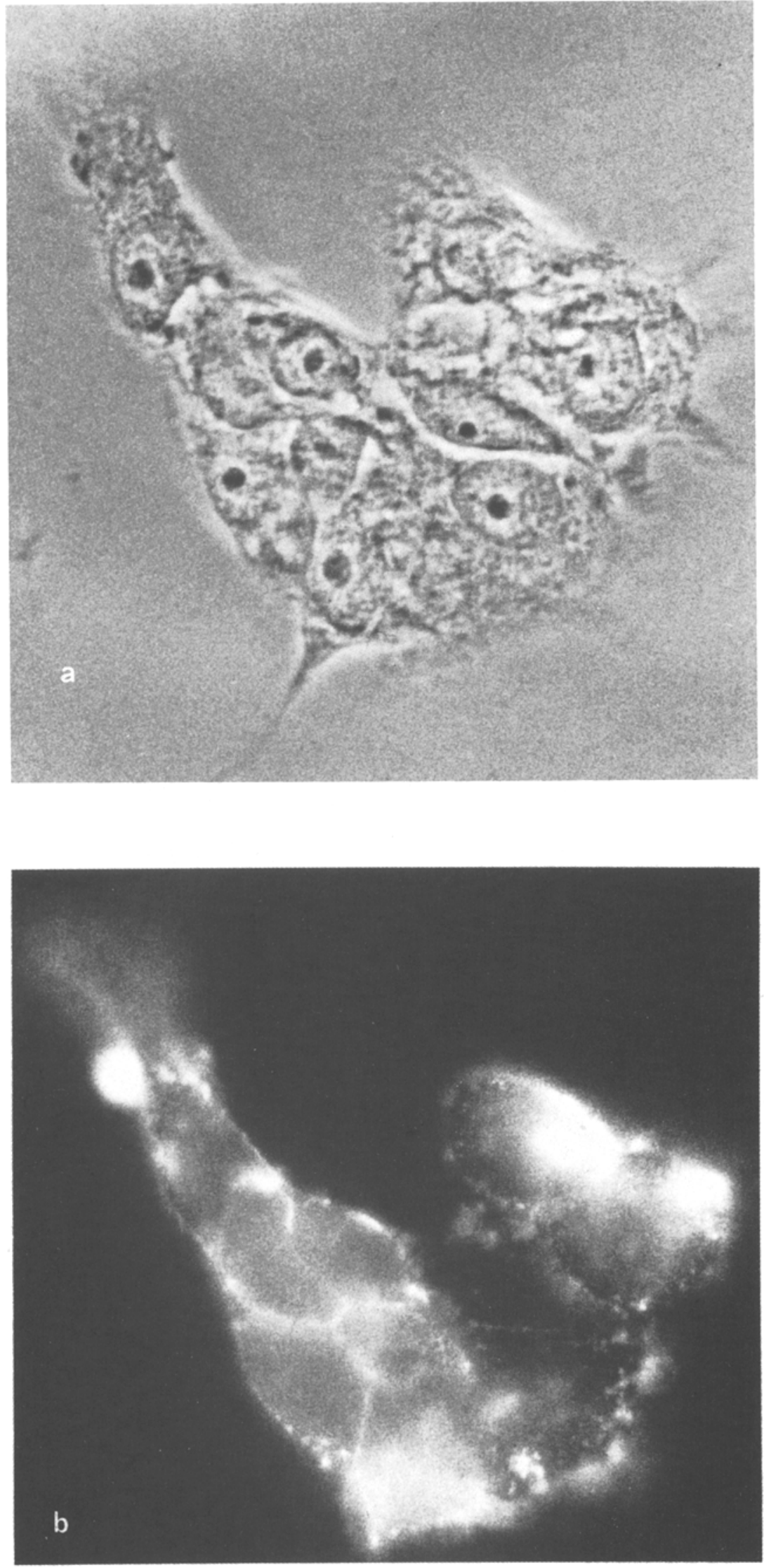

Fig. 2a-b. Four day old culture of human fetal pancreas stained with serum from a diabetic patient by indirect immunofluorescence. a phase contrast appearance of a cluster of endocrine cells. b membrane fluorescence due to ICSA showing fine bright granules typical of surface staining on living cells 
tion of these cells rarely exceeded $10 \%$ of the monolayer. They were easily distinguished visually from fibroblasts and from epithelial cells of exocrine or ductal origin. The staining of fixed cultures with a high titre ICA serum produced clear cytoplasmic fluorescence of the endocrine cells up to day 11 of culture.

Surface immunofluorescence (ICSA): when 4-7 day old viable human fetal pancreatic monolayers were incubated with some of the diabetic sera (Table 1), unequivocal surface fluorescence was observed on the endocrine cells as a fine granular pattern, denser in the less spread out cells (Figs. $2 \mathrm{a}$ and $b$ ). Absorption of the sera with blood group $\mathrm{AB}$ erythrocytes did not affect the ICSA but, removed the denser surface immunofluorescence seen sometimes on exocrine cells in the cultures and attributable to the presence of blood group antigens in these cells [14].

Further characterisation of the reaction by a double-labelled immunofluorescence staining of the plasma membrane (rhodamine) and intracytoplasmic insulin content (fluorescein) showed that the cells staining for ICSA by the diabetic sera were the insulin containing cells (Figs. $3 a$ and $b$ ). When anti-glucagon and anti-somatostatin were applied in similar experiments, results were inconclusive due to the absence of these cells in the preparation.

\section{Discussion}

This study is the first demonstration of ICSA on a normal human substrate. The high content of endocrine cells in human fetal pancreas and the relative ease with which they grow in monolayers [15] made it possible to use them as a substrate for immunological studies. The complex structure of pancreatic islets required careful identification of the cell types. This was achieved with serological markers such as hormone antisera and human autoantibodies known to react with endocrine cell autoantigens. During the steps of islet isolation and culture the proportion of endocrine cells was similar to that reported previously [16].

The fetal pancreatic islet cells released insulin during the entire culture period suggesting that there was no dedifferentiation in the in vitro system. The use of supernatants from cultures of fetal fibroblasts proved useful in reducing the period of culture necessary for the attachment of the cells to glass coverslips. Fibronectin present in fetal calf serum and released by fibroblasts is thought to be responsible for this effect which other authors have also reported [17].

The presence of ICA autoantigen as early as week 12 of gestation is interesting and supports the assump-
Table 1. Incidence of surface reative islet cell antibodies

\begin{tabular}{llll}
\hline Diagnosis & $\begin{array}{l}\text { No. of sera } \\
\text { tested }\end{array}$ & $\begin{array}{l}\text { Indirect } \\
\text { immunofluorescence on } \\
\text { viable fetal pancreas cultures }\end{array}$ \\
\cline { 2 - 4 } Positive & Negative \\
\hline $\begin{array}{c}\text { Newly diagnosed } \\
\text { Type 1 diabetics }\end{array}$ & 11 & 9 & 2 \\
$\begin{array}{c}\text { Polyendocrine } \\
\text { diabetics }\end{array}$ & 10 & 2 & 8 \\
$\begin{array}{c}\text { Non-diabetic ICA } \\
\text { positive }\end{array}$ & 1 & 0 & 1 \\
\begin{tabular}{c} 
Healthy controls \\
\hline
\end{tabular}
\end{tabular}

All the diabetic sera tested were positive for cytoplasmic ICA
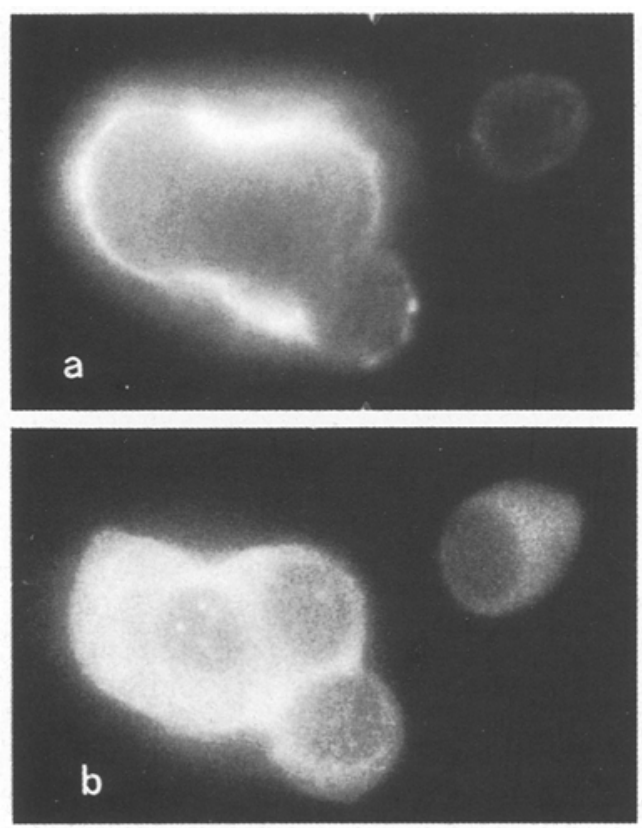

Fig. 3a-b. Six day old culture of human fetal pancreas stained by the four-layer immunofluorescence technique. a Surface staining due to ICSA demonstrated with rhodaminated antihuman-Ig. Similar appearance as in Fig. 2b. b Same cells stained with guinea-pig anti-insulin after fixation followed by a fluorescein labelled antiguinea-pig-Ig conjugate

tion that the endocrine cells are antigenically comparable to adult cells. It was possible to demonstrate the presence of the autoantigen throughout the whole culture period. The absence of $\mathrm{ABH}$ blood group reactivity in the islet cells either in sections or in cultures made it unnecessary to exclude non-blood group 0 glands from the study, on account of possible interference by membrane staining due to isohaemagglutinins [18].

The use of monolayer cultures has two advantages over that of cell suspensions as a substrate for mem- 
brane antibodies, one being the easier recognition of endocrine cells since the cytoplasm is more spread out. In addition, monolayers attached to a solid support are easier to handle. This culture method provides a suitable human substrate for the detection of ICSA in the sera of diabetics. The pattern of a fine granular surface fluorescence is similar to that observed when thyroid or adrenal autoimmune sera are applied to cultures of the respective organs $[4,6]$. Its specificity is supported by the absence of staining in non-endocrine cells and its persistence after absorption with blood group $\mathrm{AB}$ erythrocytes.

Preliminary experiments of surface staining with cells from three human insulinomas have been inconclusive in our hands. A possible explanation is that these tumour cells are far from homogeneous histologically [19] and may possess different surface antigenic determinants from a normal pancreatic substrate.

It is likely that the surface antibodies are complement-fixing since this property is well displayed in thyroid and adrenal surface reactive antibody systems $[4,6]$. In experiments with cultured insulinoma we did not succeed in showing antibody/complement mediated cytotoxicity, but this has yet to be assessed with fetal islet cultures. Using animal islet cultures, two teams have now reported cytotoxic effects with diabetic sera. In one study [20] hamster islets were subjected to diabetic sera with repeated additions of complement. Cell death at the periphery of the islets was demonstrated by Trypan blue staining. In the other study [21] newborn rat islet cells were grown in monolayers and exposed to diabetic sera and complement after 4 days in culture. Cell death was assessed by viability staining and was confined to the insulin containing cells. Antibody dependent cell mediated cytotoxicity may also be involved since lymphocyte adherence to insulinoma cells has been demonstrated by Huang and MacLaren [22] and Boitard et al. [23] have shown insulin secretion defects in mouse islets cultured with diabetic lymphocytes.

The finding that some high titre ICA positive sera failed to produce surface fluorescence in this system whereas sera with weak ICA gave strong reactions, suggests the presence of two different antigen-antibody systems, in agreement with the findings of Lernmark et al. [24], who used rat islet cells.

The fact that by double immunofluorescence we were able to localise the membrane-positive reaction in the insulin producing cells is consistent with a more direct pathogenic role for ICSA than cytoplasmic ICA. It remains to be proved that ICSA react exclusively with B cells. It has not yet been possible to establish this point due to the low number of glucagon and somatostatin cells in our monolayers. Such spe- cific reactivity might explain why $\mathrm{B}$ cells are selectively destroyed in Type 1 diabetes.

Acknowledgements. We are greatly indebted to Drs. M.Adinolfi, R. De Chazal, S. Lowler and L. Woon for the fetal tissues. We thank Professors I. M. Roitt and D. Doniach for useful discussions. Miss J. Mathews is thanked for insulin assays. Miss Queenie Jayawardena typed the manuscript. RPB and ELK were in receipt of Wellcome Trust Research Fellowships.

\section{References}

1. Bottazzo GF, Pujol-Borrell R, Doniach D (1981) Humoral and cellular immunity in diabetes mellitus. Clin Immunol Allergy 1: 139-159

2. Bottazzo GF, Doniach D (1978) Islet-cell antibodies (ICA) in diabetes mellitus: Evidence of an autoantigen common to all cells in the islets of Langerhans. Ric Clin Lab 8:29-38

3. Fagraeus A, Jonsson J (1970) Distribution of organ antigens over the surface of thyroid cells as examined by immunofluorescence test. Immunology 18:413-416

4. Khoury EL, Hammond L, Bottazzo GF, Doniach D (1981) Presence of the organ-specific 'microsomal' autoantigen on the surface of human thyroid cells in culture. Its involvement in complement-mediated cytotoxicity. Clin Exp Immunol 45: 316-328

5. Masala C, Smurra G, DiPrima MA, Amendolea MA, Celestino D, Salsano E (1981) Gastric parietal cell antibodies: demonstration by immunofluorescence of their reactivity with the surface of the gastric parietal cells. Clin Exp Immunol 22:271-280

6. Khoury EL, Hammond L, Bottazzo GF, Doniach D (1981) Surface-reactive antibodies to human adrenal cells in Addison's disease. Clin Exp Immunol 45: 48-56

7. MacLaren NK, Huang SW, Fogh J (1975) Antibody to cultured human insulinoma cells in insulin-dependent diabetes. Lancet 1:997-1000

8. Lernmark A, Freedman ZR, Hofmann C, Rubenstein AH, Steiner DF, Jackson RL, Winter RJ, Traisman HS (1978) Islet cell antibodies in juvenile diabetes mellitus. $\mathrm{N}$ Engl $\mathbf{J}$ Med 299: $375-380$

9. Goldman H, Colle E (1976) Human pancreatic islet cells in culture: effects of supplementing the medium with homologous and heterologous serum. Science 192: 1014-1016

10. Brown J, Clark WR, Makoff RK, Weisman H, KempJA, Mulleun Y (1978) Pancreas transplantation for diabetes mellitus. Ann Intern Med 89:951-965

11. Agren A, Andersson A, Bjorken C, Groth CG, Gunnarsson R, Hellerstrom C, Lindmark G, Lundqvist G, Peterson B, Swenne I (1980) Human fetal pancreas. Culture and function in vitro. Diabetes 29:64-69

12. Bottazzo GF, Dean BM, Gorsuch AN, Cudworth AG, Doniach D (1980) Complement fixing antibodies in Type 1 diabetes. Possible monitors of beta cell damage. Lancet 1:668-672

13. Doniach D, Bottazzo GF (1981) Polyendocrine autoimmunity. In: Franklin EC (ed) Clinical immunology update, vol2. Elsevier, New York, pp 95-121

14. Lendrum R, WalkerG (1975) Serum antibodies in human pancreatic disease. Gut 16:365-369

15. Lambert AE, Blondel B, Kazanawa Y, Orci L, Renold AE(1972) Monolayer cell culture of neonatal rat pancreas: Light microscopy and evidence for immunoreactive insulin synthesis and release. Endocrinology 90: 239-248

16. Like A, Orci L (1972) Embryogenesis of the human pancreatic islets: A light and electron microscopy study. Diabetes 21: 511-534 
17. Rabinovitch A, Russell T, Mintz DH (1979) Factors from fibroblasts promote pancreatic islet $B$ cell survival in tissue culture. Diabetes 28: 1108-1113

18. Khoury EL (1981) Re-expression of blood group ABH antigens on the surface of human thyroid in culture. J Cell Biol (in press)

19. Berchtold P, Berger M, Stülpnagel A, Cüppers HJ, Gries FA, Grüneklee HJ, Mitzkat HJ, MullerWA, Münterfering H, Wiegelmann W, Zimmermann H (1978) Relationship between function and morphology of insulinomas. Diabetes 27: 468 (Abstract 149)

20. Rittenhouse HG, Oxender DL, Pek S, Ar D (1980) Complement-mediated cytotoxic effects on pancreatic islets with sera from diabetic patients. Diabetes $29: 317-322$

21. Doberson MJ, Scharff JE, Ginsberg-Fellner F, Notkins AL (1980) Cytotoxic autoantibodies to beta cells in the serum of patients with insulin-dependent diabetes mellitus. N Engl J Med 303: $1493-1498$

22. Huang SW, MacLaren NK (1976) Insulin-dependent diabetes: A disease of auto-aggression. Science 192: 64-66
23. Boitard C, Debary-Sachs M, Pouplard A, Assan R (1980) Diabetic lymphocytes suppress insulin release. Diabetologia 19: 259-263

24. Lernmark A, Hägglöf B, Freedman ZR, Irvine WJ, Ludvigsson J, Holmgrem G (1981) A prospective analyses of antibodies reacting with pancreatic islet cells in insulin dependent diabetic children. Diabetologia $20: 471-474$

Received: 2 April 1981

and in revised form: 17 August 1981

Dr. G. F. Bottazzo

Department of Immunology

Middlesex Hospital Medical School

Arthur Stanley House

40-50 Tottenham Street

London WIP 9PG, UK 